\title{
A centralidade da família nos serviços de atendimento de pacientes com transtornos mentais e dependentes químicos
}

\author{
The centrality of the family in the care services of patients with mental disorders and \\ chemical dependent
}

\author{
Daniela Abreu Amaral* \\ Claudete Marlene Fries Bressan**
}

\begin{abstract}
Resumo:
O objetivo deste artigo é caracterizar a intervenção profissional do assistente social no trabalho com famílias em serviços de atendimento a pacientes com transtornos mentais e dependentes químicos. Trata-se de uma pesquisa bibliográfica, que aborda as contribuições da reforma psiquiátrica na formulação e implementação das políticas sociais públicas voltadas para saúde mental e dependência química e que visa identificar a inserção da família no processo de tratamento, particularizando a atuação do profissional de Serviço Social. A família contemporânea é entendida como uma instituição social formada por pessoas, entre as quais há laços consanguíneos, parentesco, afinidade e dependência. É, também, espaço de proteção e sobrevivência de seus membros. A atuação profissional do assistente social com as famílias na área da saúde mental e dependência química possui ênfase no trabalho com grupos, visando a troca de experiências entre os cuidadores como uma forma de potencializar e valorizar os cuidados familiares. A desconstrução de conceitos já estabelecidos socialmente relacionados a essa área de intervenção se constitui como um dos desafios para os assistentes sociais que atendem as famílias.
\end{abstract}

Palavras-chave: Família. Tratamento. Trabalho com grupos. Atuação profissional.

\begin{abstract}
:
The purpose of this article is to characterize the professional intervention of a social worker working with families in care services to patients with mental disorders and drug addicts. It is about literature search that discusses the contributions of psychiatric reform in the formulation and implementation of public social policies geared to mental health and chemical dependency and seeks to identify the family involvement in the treatment process, an emphasis on the role of Social Service professional. The contemporary family is understood as a social institution formed by people, among which there are blood ties, kinship, affinity and dependence. It is also space for the protection and survival of its members. The professional work of a social worker with families in mental health and chemical dependency has emphasis on working with groups, which aims at exchanging experiences among caregivers as a way to leverage and enhance family care. The deconstruction of concepts already established socially related to this intervention area constitutes one of the challenges for social workers serving families.
\end{abstract}

\footnotetext{
* Assistente Social graduada pela Universidade Comunitária da Região de Chapecó (Unochapecó). E-mail: daniamaral@unochapeco.edu.br

${ }^{* *}$ Assistente Social graduada pela Universidade do Contestado (UNC). Mestre em Educação pela Universidade de Passo Fundo (UPF). Especialista em Fundamentos do Serviço Social e Docência no Ensino Superior. E-mail: cbressan@unochapeco.edu.br
} 
Keywords: Family. Treatment. Working with groups. Professional performance.

\section{Introdução}

Este artigo é resultado da pesquisa realizada para a conclusão do curso de especialização (Lato Sensu) em Saúde Mental com Ênfase em Dependência Química pela Universidade Comunitária da Região de Chapecó (Unochapecó).

A relevância acadêmica deste estudo se deve ao interesse despertado durante o curso de especialização no que se refere às intervenções profissionais realizadas com as famílias de dependentes químicos e pacientes com transtornos mentais. A partir dos componentes curriculares cursados delimitamos como objetivo identificar aspectos da intervenção profissional do assistente social no trabalho com famílias no contexto da saúde mental e dependência química. Daremos enfoque para a atuação do assistente social por se tratar de um profissional que atua diretamente com a família, especialmente a inserção dessa no tratamento e no fortalecimento dos vínculos intrafamiliares.

Abordaremos a intervenção com a família de pacientes com transtornos mentais, bem como com dependentes químicos, tendo em vista que esta última é tratada pela Organização Mundial da Saúde como doença, que se caracteriza como um estado psíquico e em alguns casos também físico, resultante da interação de um organismo vivo (ser humano) e uma substância responsável por alterar o comportamento.

A centralidade da família nas políticas sociais públicas tem sido amplamente discutida e publicada em todo país, porém, carecemos de aprofundar o debate particularizando as intervenções profissionais dos assistentes sociais na atenção às famílias no tratamento para dependência química e pacientes com transtornos mentais.

No âmbito da saúde mental e dependência química, um marco importante para o trabalho nessa área foi a reforma psiquiátrica, na qual a família passou a ser reconhecida como personagem importante e essencial para o tratamento.

Ao considerar a família como elemento-chave para o processo de tratamento da dependência química e transtornos mentais, precisamos levar em conta as transformações societárias que impactaram no grupo familiar e também no cotidiano dos profissionais que trabalham com esse público, mais especificamente com os assistentes sociais. $\mathrm{O}$ artigo apresenta, inicialmente, algumas considerações sobre a reforma psiquiátrica e seus resultados 
positivos para as atuais políticas sociais públicas voltadas para saúde mental e dependência química; posteriormente, expõe o conceito de família contemporânea trabalhada pelos autores pesquisados, e, por fim, o último item discorre sobre a atuação do assistente social na área da saúde mental e dependência química.

\section{Metodologia}

O estudo compreende basicamente pesquisa bibliográfica, que conforme Dmitruk (2004, p. 68) "objetiva levantar informações sobre temas e abordagens já trabalhados por outros pesquisadores, analisando as contribuições teóricas sobre o tema e a problemática de interesse". Consiste, assim, em um estudo a partir de material já elaborado por outros pesquisadores sobre o tema delimitado.

O caráter do estudo é predominantemente qualitativo, pois as informações coletadas a partir da pesquisa bibliográfica serão analisadas de modo a descrever as características subjetivas relacionadas às contribuições do Serviço Social no trabalho com famílias acerca da temática da saúde mental e da dependência química. A seleção dos autores e obras pesquisadas foi intencional, mas também encontrou limites considerando a pouca publicação sobre o tema em questão.

Optamos por recorrer a artigos publicados em livros e coletâneas, sendo que alguns foram trabalhados durante o curso de especialização. Os artigos que escolhemos como base para a elaboração da pesquisa foram: "A família como usuária de serviços e como sujeito político no processo de reforma psiquiátrica" (ROSA, 2009); "Inserções do assistente social em saúde mental: em foco o trabalho com as famílias" (ROSA; MELO, 2009); "O uso abusivo de álcool e outras drogas na sociedade brasileira e seus rebatimentos no âmbito da família: breves considerações" (REIS, 2005); e "Famílias e dependência de drogas: interfaces com as políticas públicas" (GOULART; SOARES, 2013). Ressaltamos que os dois primeiros artigos estão voltados para pacientes com transtornos mentais e os dois últimos abordam a família no tratamento de dependentes químicos.

\section{Resultados e discussões}

Os autores pesquisados, ao tratar da família no contexto da saúde mental e dependência química, fazem referência à reforma psiquiátrica como marco importante para 
as atuais políticas sociais públicas que atendem familiares e pacientes com transtornos mentais e dependentes químicos, uma vez que trouxe mudanças significativas nas diretrizes dos estabelecimentos a esse público.

Com a aprovação da lei 10.216, de 06 de abril de 2001 (BRASIL, 2001), também conhecida como a Lei Psiquiátrica, o objetivo do tratamento passou a ser a reabilitação do paciente ou, então, o máximo de melhora para a sua reinserção na família, na comunidade e, quando possível, no trabalho. Além disso, as informações acerca da doença e do tratamento devem ser devidamente esclarecidas ao paciente. Com a reforma psiquiátrica, a internação não é mais prioridade na saúde mental, pois só será realizada quando todas as demais formas de tratamento forem descartadas pelo médico e pela equipe. Conforme prevê o artigo 4ํ "a internação, em qualquer de suas modalidades, só será indicada quando os recursos extrahospitalares se mostrarem insuficientes" (BRASIL, 2001). Além do mais, o tratamento deve ser realizado por meio de uma equipe multiprofissional e que preste atendimento integral envolvendo várias políticas sociais. A lei, em seu artigo 4으, §3ํ, também afirma que é proibida a internação de paciente em instituições com características asilares, reafirmando a prioridade de realização do tratamento no meio familiar, com o suporte técnico dos serviços e políticas públicas tanto para a família quanto para o paciente.

Rosa (2009) faz referência à portaria no. 251/GM, de 31 de janeiro de 2002 (BRASIL, 2002), como um passo importante na trajetória da saúde mental no Brasil. Nessa portaria fica estabelecida a nítida mudança nas relações entre os serviços de psiquiatria e a família, pois até então os familiares eram vistos como "informantes; como um recurso episódico ou como uma visita, muitas vezes, inconveniente". Com a referida portaria, fica previsto que nos projetos terapêuticos é necessário "o preparo para o retorno à residência/inserção domiciliar e uma abordagem dirigida à família com o propósito de garantir orientação sobre o diagnóstico, o programa de tratamento, a alta hospitalar e a continuidade do tratamento" (ROSA, 2009, p. 161).

Goulart e Soares (2013) apontam a reforma psiquiátrica como base para a atual atenção às pessoas e famílias que enfrentam problemas com a dependência, pois os serviços que prestam atendimento têm como pressuposto tratamentos ambulatoriais nos moldes da redução de danos e, principalmente, pautados na garantia dos direitos dos pacientes e familiares. Os autores afirmam, também, que tais direitos só poderão ser garantidos "a partir 
do momento em que se estruture uma rede de cuidados intersetorial, que trabalhe com a lógica da diminuição dos fatores de risco e ampliação dos fatores de proteção, respeitando a diversidade e complexidade" das famílias e também à dependência de álcool e outras drogas (GOULART; SOARES, 2013, p. 3).

O grupo familiar passa a ser reconhecido como provedor de cuidados para membro com transtorno mental, tornando fundamental a sua inserção nas ações desenvolvidas nos serviços de atendimento a pessoa com transtorno mental. Vale destacar que, nos debates ocorridos durante a reforma psiquiátrica, a família era entendida por várias dimensões e sentidos, entre os principais, por um grupo que necessita de cuidados e assistência, como provedora de cuidados e avaliadora dos serviços. Mais recentemente, ela foi incluída nos debates como sujeito político, pois "se organiza e luta por direitos" e é um recurso fundamental para o êxito no tratamento (ROSA, 2009, p. 166).

Em consideração às mudanças ocorridas com a reforma psiquiátrica no que se refere à inserção das famílias nos processos de tratamento, nos serviços que atendem pacientes com transtornos mentais e dependentes químicos, é importante que os profissionais que atuam na área da saúde mental e da dependência química tenham clareza das discussões contemporâneas acerca da família, pois o êxito das ações depende da postura adotada e condução do trabalho realizado.

Bruschini (1989, apud ROSA, 2009, p. 166-167) trabalha com o conceito de família na concepção sociológica, entendendo-a como

[...] o conjunto de pessoas ligadas por laços de sangue, parentesco ou dependência que estabelecem entre si relações de solidariedade e tensão, conflito e afeto [...] como uma unidade de indivíduos de sexo, idade e posições diversificadas, que vivenciam um constante jogo de poder que se cristaliza na distribuição de direitos e deveres.

Assim, a família é conhecida por um grupo de pessoas que possui interesses diversos e por isso é um espaço de disputa entre os membros.

Soares e Neves (2009, apud GOULART; SOARES, 2013) abordam a família como uma instituição social que "é constantemente afetada pelas alterações vivenciadas nas diversas sociedades, com seus respectivos valores, posicionamentos ideológicos e relações sociais, não podendo ser compreendida como uma instância neutra, estática, acabada e uniforme". Ela é 
entendida, portanto, como uma unidade inacabada que se transforma conforme as mudanças ocorridas na sociedade, dentro de uma perspectiva dialética.

Rosa (2009) argumenta que a revitalização do tema família está associada às transformações que vem passando nas últimas décadas. Nesta perspectiva, cita como exemplo a reestruturação produtiva que acarretou o desemprego de indivíduos que passaram a considerar a família como espaço de vínculo e referência social, da mesma maneira que um espaço de cuidado e sobrevivência. A autora cita ainda as políticas neoliberais, que podem ser entendidas como a redução da intervenção do Estado na área social e a retomada do mercado como principal regulador da economia. Tais políticas impactaram regressivamente nas políticas sociais de modo a atribuir funções, que antes eram exclusivas do Estado, para a família.

Segundo Mesquita (2011), o Estado transfere para a família a responsabilidade do bemestar de seus membros e a proteção social, que até então era entendida como responsabilidade coletiva. Essa passa a ser substituída pela individualização, em que cada família é responsável pelo bem-estar dos seus membros, podendo contar com o apoio estatal quando sua capacidade protetiva estiver fragilizada. Dessa forma, o Estado assume que a família deve ser apoiada e ter acesso às condições básicas para responder ao seu papel e cumprir com suas funções de cuidado, por isso surgem as políticas sociais públicas e programas governamentais que dão ênfase na matricialidade da família. Contudo, as intervenções não ocorrem somente por parte do Estado, pois, como vimos, a ideologia neoliberal prevê a sua redução para a área social, dando espaço e estimulando que o mercado e a sociedade civil atuem nesse meio.

Conforme afirma Mioto (2010, p. 170), o Estado se desvia da rota de "garantia dos direitos sociais através de políticas públicas de caráter universal e entra na rota da focalização das políticas públicas nos seguimentos mais pauperizados da população", fortalecendo o mercado como uma instância de provisão de bem-estar social, apostando também na sociedade civil organizada para provê-lo. Com isso, percebemos políticas públicas e programas governamentais focalizados e destinados a segmentos pauperizados, muito longe de alcançar a universalidade e de atender toda a demanda.

Diante da insuficiência de políticas públicas, materializadas em serviços, outros atores assumem o apoio e fortalecimento da família para que se possa garantir o bem-estar aos seus 
membros, como, por exemplo, as organizações não governamentais, associações, fundações, entre outras.

Com relação às transformações ocorridas na família, Reis $(2005$, p. 8) também afirma que estão relacionadas às mudanças no padrão de acumulação capitalista ocorridas nas décadas de 1960 e 1970 e à entrada maciça da mulher no mercado de trabalho, em decorrência da necessidade econômica e também do desejo de realização pessoal.

Além dessas transformações, identificamos o aumento das separações conjugais e os novos arranjos familiares. Jelin (1994, apud REIS, 2005, p. 8-9) analisa, de um outro ponto de vista, as separações relacionadas a uma série de fatores, entre eles

[...] diminuição do número de membros; postergação da idade para casar-se; aumento de uniões consensuais; de casamentos de noivas grávidas; de filhos extramatrimoniais; de separações e divórcios; de lares formados por um casal sem filhos, outros, por uma mãe e seus filhos, sem pai; [...] de lares reconstituídos [...] de lares nos quais os filhos participam das conversações do redor da mesa [...].

As transformações indicam ainda a presença de um diálogo mais estreito entre pais e filhos, o que pode ser um indício de relações mais democráticas entre os membros familiares. Contudo, é importante perceber essas relações no interior das famílias vinculadas a valores individuais, característica presente na sociedade contemporânea.

Com os valores associados ao individualismo, cada sujeito passou a olhar mais para si próprio, para seus interesses e dos grupos aos quais pertencem. Se no modelo patriarcal era o pai quem detinha o poder, com as transformações já mencionadas, os filhos, cada vez mais, estão em busca de uma autonomia pessoal e financeira. Assim, a família passa a ser composta por indivíduos com afinidades, mas, também, que desejam "fazer valer seus desejos e aspirações" (REIS, 2005, p. 10).

A família é entendida, nas novas composições familiares, por uma instituição social composta por pessoas ligadas por laços afetivos, consanguíneos e de afinidade, reconhecida pela função de socialização, cuidado, proteção e sobrevivência de seus membros, mas também se caracteriza como um espaço de disputa e de conflito entre os membros.

Apesar de todas as mudanças, a família continua sendo o espaço em que as pessoas se reproduzem biologicamente e socialmente. Neste sentido, Goulart e Soares $(2013$, p. 4) afirmam que o ambiente familiar é "a base de construção da cidadania de cada indivíduo, 
independentemente do seu modelo, pois traz possibilidades que vão desde as associadas a fatores de proteção, socialização até a criação de vínculos essenciais aos indivíduos".

Carvalho (2002, p. 15) argumenta que a maior expectativa com relação à família é que a essa produza "cuidados, proteção, aprendizado dos afetos, construção de identidades e vínculos relacionais de pertencimento, capazes de promover melhor qualidade de vida a seus membros e efetiva inclusão social na comunidade e sociedade em que vivem". Porém, essas expectativas são possibilidades e não garantias, já que nem todas as famílias têm acesso à educação de qualidade, saúde, moradia, saneamento básico, entre outros serviços, em razão da desigualdade social.

A Constituição Federal de 1988 (BRASIL, 1988) prevê em seu artigo 226 que a família é a base da sociedade e tem proteção especial do Estado, de maneira que este tem a obrigação legal de estabelecer políticas sociais públicas de proteção integral às famílias.

Para dar materialidade à Constituição Federal de 1988, a Política Nacional sobre Drogas (BRASIL, 2005) e a Política Nacional de Saúde Mental (apoiada pela lei 10.216, de 6 de abril de 2001) prezam pelo atendimento integral ao paciente, tendo como diretriz a inserção da família no tratamento e acompanhamento no processo de recuperação e reinserção na sociedade. Para tanto, o Ministério da Saúde dispõe de alguns serviços que priorizam o atendimento aos familiares e a sua participação no tratamento, tais como os Centros de Atenção Psicossocial (CAPS) e as Comunidades Terapêuticas.

Ao discorrerem sobre família na temática da dependência química e saúde mental, os autores tratam-na como fator de proteção e trabalham também com algumas potencialidades que podem ser desenvolvidas a partir de uma intervenção qualificada.

Rosa e Melo (2009, p. 97) afirmam que a família, durante a fase inicial do transtorno mental, tem um papel fundamental na "construção de uma nova trajetória para o seu ente enfermo, desde que seus recursos emocionais, temporal e econômico sejam bem direcionados pelos trabalhadores e serviços da saúde mental". Porém, nenhuma família está preparada para ter um paciente com transtorno mental ou então um dependente químico, sendo que com esse acontecimento algumas complexidades se manifestam, entre elas

[...] no imaginário da sociedade moderna, é previsto que uma pessoa adulta seja emancipada, tenha incorporado o autocuidado e seja independente, não necessitando de cuidados de terceiros. [...] tratar de uma pessoa adulta, com transtorno mental, no ambiente doméstico é uma tarefa complexa, que exige 
preparo mínimo do cuidador, para lidar com uma gama imensa de ocorrências. [...] os grupos familiares são demandados a se reposicionar em relação a uma série de questões envolvendo inclusive sentimentos (ROSA; MELO, 2009, p. 97-98).

Esses conceitos construídos socialmente, em muitas situações, tendem a causar um sentimento de impotência na família, por isso, é importante que os serviços estejam preparados para acolher os familiares cuidadores e fortalecê-los emocionalmente para que possam desconstruir os imaginários que perpassam o cotidiano dessas famílias.

Rosa (2009, p. 161) também ressalta que os saberes da família e os recursos emocionais para trabalharem nos cuidados precisam ser bem direcionados. Para tanto, a contribuição dos trabalhadores e dos serviços públicos são fundamentais para desconstruir a ideia existente na sociedade, e, portanto, partilhada pelas famílias, de que "lugar de louco é no hospício". É necessária uma atuação intensa dos profissionais com as famílias no sentido de fortalecê-las para continuar a desempenhar a função de cuidadores.

Quando bem orientada, a família pode ser a ponte entre o paciente e a instituição de tratamento, pois a convivência intrafamiliar poderá contribuir com os profissionais nas metodologias adequadas de tratamento.

Com relação à dependência química, Goulart e Soares (2013) afirmam que a família deve ser entendida como eixo primário das relações que possibilitam a efetividade do tratamento e acompanhamento do depende químico e não mais como a causa ou agente que leva ao uso de drogas. Defendem, ainda, a necessidade de ações que promovam o fortalecimento da família enquanto fator de proteção na prevenção e atenção à questão da dependência de álcool e outras drogas.

Nesse sentido, a família deve ser vista "como ator social que constrói, configura e integra a realidade social, por meio de sua expressividade em relação à saúde mental e à dependência ao álcool e outras drogas" (ROSA, 2003, apud GOULART; SOARES, 2009, p. 8).

Na maioria dos casos, quando procuram os serviços públicos ou mesmo privados, os familiares se encontram fragilizados emocionalmente. Rosa destaca $(2009$, p. 168) que "a família que procura a assistência psiquiátrica, no geral, está em um contexto de crise, e uma crise já instalada, com uma história e várias tentativas, sem êxito, para debelá-la". Dessa forma, a família tenta resolver os problemas que surgiram no seu espaço privado recorrendo a seus próprios meios particulares com estratégias que já foram eficazes em outras situações. Quando não consegue resolvê-los no meio interno, tende a procurar parentes próximos, 
vizinhos e autoridades locais (padre, pastor, benzedeiras etc.). Esgotadas também essas estratégias, a família procura um serviço público e "normalmente, essa família chega a um serviço psiquiátrico com sentimento de impotência, exaustão, culpa, desespero", sendo "uma das últimas formas de publicizar uma questão que preferia, se tivesse outra opção, resolver no plano privado" (ROSA, 2009, p. 168).

Nessa perspectiva de ação, os serviços precisam dispor de um espaço e metodologia de acolhida para a família, esclarecendo o lugar que ocupa na recuperação de seu membro de modo a acompanhá-la, fortalecê-la emocionalmente e inseri-la no tratamento.

\section{A atuação do Assistente Social na saúde mental}

Segundo Rosa e Melo (2009, p. 84), a inserção do assistente social na área da saúde mental teve início em 1946, primeiramente em instituições voltadas à infância e posteriormente em hospitais psiquiátricos. No espaço hospitalar, as ações profissionais prevaleciam nos levantamentos de dados sociais dos pacientes com transtornos mentais e seus familiares, "confecção de atestados sociais, encaminhamentos para a rede socioassistencial e difusão de informação e orientação social" principalmente para regularizar a documentação pessoal, visando acessar benefícios sociais ou aposentadorias. Já nos serviços que resultaram da reforma psiquiátrica, como os CAPS, as residências terapêuticas e até mesmo nos serviços de atenção básica, a atuação dos assistentes sociais ocorre em uma diversidade de funções, como, por exemplo, na gestão, planejamento, coordenação, supervisão, entre outros.

Além dos espaços públicos, a requisição pelo profissional se dá também em empresas privadas como hospitais e clínicas, o que justifica sua constante atualização e aprimoramento na área da saúde mental e dependência química.

A Constituição Federal de 1988, em seu artigo 226, reconhece que a família é a base da sociedade e que por isso "tem especial proteção de Estado" (BRASIL, 1988). Essa proteção se dá a partir das políticas públicas em que o assistente social está inserido para garantir direitos sociais à população que se encontra em situação de vulnerabilidade social, dando ênfase à família. Assim, o grupo familiar vem sendo, cada vez mais, fundamental e responsável pela formação e pelo desenvolvimento dos cidadãos, fato pelo qual o Estado prevê políticas públicas visando sua proteção. 
As ações voltadas às famílias na área da saúde mental e da dependência química se baseiam em um trabalho psicossocial, que preza pelo respeito "aos arranjos familiares, aos valores, crenças e identidade das famílias e se fundamenta no fortalecimento da cultura, do diálogo, no combate a todas as formas de violência, de preconceito, de discriminação e nas relações familiares". Tais ações objetivam, também, a potencialização dos recursos disponíveis nas famílias, "suas formas de organização, sociabilidade e redes informais de apoio para o fortalecimento ou resgate de sua autoestima e a defesa de direitos". (GOULART; SOARES, 2013, p. 5).

Diante da complexidade que abrange o espaço familiar, Goulart e Soares (2013) ressaltam a importância de os profissionais compreenderem a família em sua totalidade a partir da perspectiva crítico-dialética, que considera o constante movimento e as transformações pelas quais passou, entendendo-as como resultados de relações complexas e contraditórias estabelecidas na sociedade no processo de produção e reprodução das relações sociais. Cabe ao profissional respeitar os diferentes contextos e relações familiares, de modo a não julgar e não agir cerceando a autonomia e a forma como se organiza nos cuidados. Esse posicionamento está previsto no Código de Ética Profissional do/a Assistente Social (BRASIL, 2011 , p. 23), que tem como um dos princípios fundamentais o "reconhecimento da liberdade como valor ético central e das demandas políticas a ela inerentes - autonomia, emancipação e plena expansão dos indivíduos sociais", reforçando que os sujeitos são livres em suas escolhas, e os profissionais em suas intervenções devem reforçar a autonomia dos usuários.

A presente pesquisa permitiu identificar que a atuação dos assistentes sociais na área da saúde mental e dependência química apontam para o trabalho com grupos de familiares, sendo a família parte do cotidiano do assistente social, por isso, requisita-se de suas abordagens ações que possibilitem melhores resultados para as diferentes demandas que as transformações societárias vêm impondo às famílias, de modo a articular as diferentes políticas sociais de atendimento e suporte às necessidades dessas.

Rosa e Melo (2009, p. 99-100), ao abordarem o trabalho do assistente social com o grupo familiar, afirmam que a profissão contribui por meio do trabalho socioeducativo, que promove a troca de informações e de vivências, visando, além de tudo, que os "cuidadores familiares saiam de seu isolamento pessoal e social, tendo sua carga de trabalho aliviada, apoiada". Quando os familiares passam a trocar informações com outros cuidadores 
percebem que as vivências e os sofrimentos de muitas pessoas são semelhantes às suas e que as experiências vividas por outros cuidadores podem servir de apoio para o enfrentamento das situações vividas.

No trabalho com grupos de familiares é necessário que seja construído um espaço para a troca de vivências dessas pessoas, pois "potencializa novas estratégias de cuidado", uma vez que não há um receituário que ensine como cuidar do paciente. A reconstrução das trajetórias de vida dos familiares pode ser uma das respostas para os desafios que os cuidadores procuram cotidianamente, podendo, ainda, potencializar o conhecimento que produziram enquanto cuidadores, mas que muitas vezes não reconhecem como tal (ROSA; MELO, 2009, p. 100).

Neste sentido Rosa e Melo (2009) e Rosa (2009) chamam a atenção para alguns cuidados que o profissional precisa ter ao trabalhar com os grupos, pois em determinadas situações os familiares chegam às reuniões com a expectativa de que o assistente social ou os demais profissionais que atuam nesses grupos solucionem o seu problema. Há, muitas vezes, no imaginário popular o entendimento de que os profissionais - especialmente aqueles de nível superior - estariam mais aptos a cuidar dos pacientes. É primordial que se quebre esse paradigma e que as potencialidades dos cuidadores sejam desveladas, que reconheçam a experiência que possuem nos cuidados como um conhecimento fundamental para o tratamento e recuperação do familiar.

Rosa (2009) argumenta que a família em crise tende a transferir a resolução do problema para o profissional e este precisa estar atento para não entrar no dilema de se sentir na obrigação de dar uma resposta ou encontrar uma solução. É preciso posicionamento ético para não interferir nas decisões da família, de modo a evitar opinar e agir de maneira autoritária, limitando a autonomia das famílias.

Goulart e Soares (2013, p. 8) se referem aos encontros grupais como "grupos de apoio" que, por sua vez, devem funcionar dentro de uma rede intersetorial, pois "quando familiares em situações de crise encontram outros familiares que conseguem ter posturas diferentes e que já possuem retornos positivos, há um aumento da motivação para a mudança e da confiança no processo de tratamento". Desta forma, é necessário que os profissionais apostem nos grupos como uma forma de apoio às famílias, levando em conta suas vivências e saberes desde as orientações até o tratamento e a reinserção social do paciente. 
A Política do Ministério da Saúde para a atenção integral a usuários de álcool e outras drogas (BRASIL, 2003) prioriza o atendimento a família, chamando-a a participar na prevenção e no tratamento da problemática do uso de drogas, juntamente com outros protagonistas, como a comunidade e demais serviços e políticas públicas, ou seja, a rede social ${ }^{1}$.

Torna-se necessária a "estruturação e fortalecimento de uma rede de assistência centrada na atenção comunitária associada à rede de serviços de saúde, sociais e demais políticas intersetoriais, que tenha ênfase na reabilitação e reinserção social dos seus usuários" (GOULART; SOARES, 2013, p. 6).

Essa rede passa a integrar as políticas públicas de modo que os atores que a representam devam compartilhar a responsabilidade nos cuidados com os usuários assegurando também a atenção integral às famílias. Particularizando a dependência química, Goulart e Soares (2013, p. 9) afirmam que o grupo familiar deve assumir o papel como um dos atores sociais desta rede para que se distancie "da posição de assistido, tutelado e apenas receptor de ações", tornando-se, assim, parte do processo e protagonista na afirmação e consolidação desta rede de atenção e cuidados.

O trabalho na área da dependência química e da saúde mental não se realiza de forma isolada, pois faz-se necessária a articulação com as demais políticas públicas que também compõem a proteção integral à família por parte do Estado - prevista no artigo 226 da Constituição Federal de 1988. Além dos serviços públicos, a rede é composta, ainda, pelas comunidades e organizações não governamentais. Contudo, é preciso ter clareza de que a participação da sociedade civil na rede social de apoio à família não significa a desresponsabilização do Estado para com suas obrigações em relação à saúde mental.

A desresponsabilidade do Estado para com a saúde mental pode ser, como adverte Reis (2005, p. 15), “facilitadora do surgimento de um discurso de 'culpabilização' da família, colocando sobre a mesma grande parte da responsabilidade sobre a presença do usuário de drogas no seu interior".

\footnotetext{
${ }^{1}$ Neves (2009, p. 149) conceitua rede social a partir de várias perspectivas, entre elas a sociologia que aborda as redes sociais no mundo dos negócios, que, por sua vez, consideram as "inter-relações, associações encadeadas, interações, vínculos não hierarquizados, todos estes aspectos envolvendo relações de comunicação, assim como o intercâmbio de informações e trocas diversas". Amaral (2014, p. 1) conceitua rede como um "sistema aberto \& fechado, cujos elementos estão relacionados entre si por regras, dispositivos, artefatos e situações de comunicação não subordinada. Compartilham objetivos e tarefas comuns e, na conectividade, geram dinâmicas de auto-organização".
} 
O trabalho com famílias no campo da saúde mental deve levar em consideração outro aspecto importante: a tendência de enxergar somente a pobreza, a impotência e a impossibilidade da família. Podemos afirmar que esse posicionamento é um risco ou mesmo um equívoco do profissional diante do atendimento a uma família em situação de crise. Rosa $(2009$, p. 176) ressalta que quando isso ocorre o profissional pode ficar tão estagnado, fazendo com que ele não perceba as possibilidades existentes na família e também na intersetorialidade com as demais políticas públicas. Para a autora, a "circunstância de crise é a ocasião em que o grupo familiar mostra toda a sua incapacidade, impotência, mas é também, a ocasião em que estão afloradas várias capacidades que o próprio grupo [...] não consegue identificar".

O profissional, a partir de sua bagagem teórica, postura ética e instrumentais técnicooperativos, deve entender a família como um grupo social em que os membros são capazes de organizar e reorganizar suas demandas e necessidades dentro de seu meio, podendo, ainda, reconstruir os vínculos ameaçados por meio do apoio recebido dos serviços das políticas públicas.

O empoderamento das famílias tem sido um tema amplamente discutido nas políticas públicas, tendo em vista que para o enfrentamento das suas vulnerabilidades é necessário potencializar suas competências. Na saúde mental e na dependência química, os profissionais precisam recorrer a metodologias que estimulem o protagonismo e o empoderamento das famílias, visando a superação de suas dificuldades e fragilidades e estimulando que essas se percebam parte do processo orientado por profissionais.

O estímulo ao protagonismo, a autonomia e ao empoderamento requer instigar a participação dos membros familiares e pacientes para participar das decisões a serem tomadas, considerando a possibilidade de organização das famílias. Os profissionais devem ainda formular propostas de reflexões relacionadas ao contexto em que estão inseridos. Para tanto, a aproximação com os familiares é fundamental para conhecer a realidade e se pensar estratégias de participação e protagonismo das famílias.

\section{Considerações finais}

A partir do estudo realizado, consideramos que a reforma psiquiátrica passou a valorizar a família no processo de tratamento e recuperação de pacientes com transtornos mentais e 
dependentes químicos e, por isso, atualmente os serviços preveem a inserção da família nos planos de tratamento. As políticas sociais públicas de atendimento à saúde mental e dependência química prezam pelo atendimento as famílias e cada vez mais a matricialidade familiar tem sido discutida no âmbito das políticas públicas. Ocorre que, embora muito se tenha avançado nos serviços de atendimento ao grupo familiar, as políticas públicas são fragmentadas e focalizadas, fato pelo qual nem sempre as famílias são alcançadas pelos serviços. Outro aspecto relevante é a compreensão acerca da instituição familiar que nem sempre é reconhecida pelas políticas públicas.

O trabalho com famílias exige um preparo e conhecimento profissional acerca do tema. Há de ser ter o cuidado para não responsabilizar os membros familiares e entender que nenhuma família se prepara para ter um membro doente e por isso é importante dar suporte a ela.

Superar verdades tidas como definidas são desafios tanto para os profissionais quanto para as famílias, entre as principais, a ideia de que o atendimento nas instituições de abrigo e internação é melhor que os cuidados que a família pode despender ao paciente. Uma família devidamente amparada por profissionais qualificados pode se fortalecer e ser, de fato, um fator de proteção aos pacientes com transtornos mentais e dependentes químicos.

O trabalho com grupos de apoio aos familiares dos pacientes com transtornos mentais ou dependentes químicos se destaca como um espaço importante e relevante de ajuda mútua. Esse trabalho é uma das atribuições fundamentais para a acolhida, fortalecimento emocional dos participantes a partir da troca de experiência e identificação de suas potencialidades e dificuldades diante do contexto da saúde mental e dependência química. É necessário que os profissionais, em suas intervenções, entendam o grupo familiar a partir da perspectiva crítico-dialética, de modo a considerar as transformações, os movimentos realizados e as particularidades subjetivas das famílias.

A contribuição do Serviço Social no trabalho com famílias se dá principalmente no fortalecimento de vínculos entre familiares e pacientes, potencialização dos recursos que a família possui nos cuidados, valorização dos cuidadores e desconstrução de alguns conceitos preestabelecidos socialmente. Há de se levar em consideração que as famílias ao procurarem os serviços, na maioria das vezes, encontram-se fragilizadas e munidas de conceitos socialmente construídos, com a percepção de que os profissionais são os responsáveis pelo 
tratamento e recuperação. Nesse sentido, é imprescindível um trabalho de acolhida, valorização e identificação de potencialidades e fragilidades do grupo familiar no contexto da doença. Esse trabalho se realiza pautado na autonomia dos usuários e protagonismo das famílias cuidadoras, de modo que o profissional atue respeitando e estimulando as diversidades e o empoderamento dos cuidadores.

O estudo em questão foi bibliográfico e por isso ainda restaram aspectos que podem ser aprofundados em estudos futuros. Durante a pesquisa, evidenciamos que são poucos os estudos e experiências que relatem o trabalho do assistente social na saúde mental e dependência química, o que acabou por restringir nossa pesquisa a poucos autores. Entre os aspectos que merecem ser aprofundados para expandir os conhecimentos a respeito da atuação do assistente social nessa área são: o entendimento dos profissionais acerca do trabalho com famílias; as principais intervenções realizadas; as principais dificuldades e potencialidades das famílias no contexto da dependência química e da saúde mental.

\section{Referências}

AMARAL, V. Rede: uma abordagem operativa. Disponível em: <http://www.rits.org.br/redes_teste/rd_tmes_mar2007.cfm>. Acesso em: 29 jun. 2014.

BRASIL. Constituição da República Federativa do Brasil de 1988. Disponível em: <http://www.planalto.gov.br/ccivil_03/constituicao/constituicao.htm>. Acesso em: 18 jun. 2014.

Lei no 10.216, de 6 de abril de 2001. Dispõe sobre a proteção e os direitos das pessoas portadoras de transtornos mentais e redireciona o modelo assistencial em saúde mental. Disponível em: <http://www.planalto.gov.br/ccivil_03/leis/leis_2001//10216.htm>. Acesso em: 10 jun. 2014.

Portaria no 251/GM de 31 de janeiro de 2002. Estabelece diretrizes e normas para a assistência hospitalar em psiquiatria, reclassifica os hospitais psiquiátricos, define e estrutura, a porta de entrada para as internações psiquiátricas na rede do SUS e dá outras providências. Disponível em: <http://dtr2001.saude.gov.br/sas/PORTARIAS/Port2002/Gm/GM-251.htm>. Acesso em: 10 jun. 2014.

Ministério da Saúde. Secretaria de Atenção à Saúde. Coordenação Nacional DST/AIDS. A política do ministério da saúde para a atenção integral a usuários de álcool e outras drogas. Brasília: Ministério da Saúde, 2003.

- Ministério do Desenvolvimento Social e Combate à Fome. Política nacional de assistência social: norma operacional básica NOB/SUAS. Brasília: Secretaria Nacional de Assistência Social, 2005. 
. Código de ética do assistente social. 9. ed. Brasília: Conselho Federal de Serviço Social, 2011.

CARVALHO, M. C. B. (Org.). A família contemporânea em debate. São Paulo: EDUC, 2002.

DMITRUK, H. B. (Org.). Cadernos metodológicos: diretrizes do trabalho científico. 6. ed. Chapecó: Argos, 2004.

GOULART, D. C. S.; SOARES, A. C. N. Famílias e dependência de drogas: interfaces com as políticas públicas. In: SIMPÓSIO MINEIRO DE ASSISTENTES SOCIAIS, 3., 2013, Belo Horizonte. Anais... Belo Horizonte, 2013. Disponível em: <http://www.cressmg.org.br/arquivos/simposio/FAM\%C3\%8DLIAS\%20E\%20DEPEND\%C3\%8ANCIA\%20DE\%20D ROGAS.pdf>. Acesso em: 20 jun. 2014.

MESQUITA, A. P. A família como centralidade nas políticas públicas: a constituição da agenda e as rotas de reprodução das desigualdades de gênero. In: CONFERÊNCIA DO DESENVOLVIMENTO - CODE, 2., 2011, Brasília. Anais... Brasília: IPEA, 2011. Disponível em: <http://www.ipea.gov.br/code2011/chamada2011/pdf/area2/area2-artigo29.pdf>. Acesso em: 16 jul. 2014.

MIOTO, R. C. T. Família, trabalho com família e serviço social. Serviço Social em Revista, Londrina, v. 12, n. 2, p. 163-176, jun. 2010. Disponível em:

<http://www.uel.br/revistas/uel/index.php/ssrevista/article/view/7584/6835>. Acesso em: 23 jul. 2014

NEVES, M. N. Rede de atendimento social: uma ação possível? Revista da Católica, Uberlândia, v. 1, n. 1, p. 147-165, 2009. Disponível em:

$<$ http://catolicaonline.com.br/revistadacatolica2/artigosv1n1/13_Rede_de_atendimento.pd f>. Acesso em: 15 jul. 2014.

REIS, T. R. O uso abusivo de álcool e outras drogas na sociedade brasileira e seus rebatimentos no âmbito da família: breves considerações. Revista Ágora, Rio de Janeiro, v. 2, n. 1, dez. 2005.

ROSA, L. C. S. A família como usuária dos serviços e como sujeito político no processo de Reforma Psiquiátrica. In: VASCONCELOS, E. M. (Org.). Abordagens psicossociais: perspectivas para o serviço social. São Paulo: Hucitec, 2009. p. 159-182.

; MELO, T. M. F. S. Inserções do assistente social em saúde mental: em foco o trabalho com as famílias. Revista Serviço Social \& Saúde, Campinas, v. 7-8, n. 7-8, p. 75-106, dez. 2009. Disponível em:

<http://www.bibliotecadigital.unicamp.br/document/?code=46153\&opt=1>. Acesso em: 1 jul. 2014.

Recebido em: 25/05/2015

Aprovado em: 22/06/2015 